\title{
GAMBARAN PENDIDIKAN SEKSUAL ANAK USIA DINI DALAM KELUARGA PADA KELUARGA SEJAHTERA III PLUS KECAMATAN TALLO KOTA MAKASSAR
}

\author{
Nurdiyanah $^{1}$, Fatmawaty Mallapiang ${ }^{2}$, Nildawati, Aulia Rahma ${ }^{3}$ \\ ${ }^{1,4}$ Bagian Promosi Kesehatan Universitas Islam Negeri Alauddin Makassar \\ ${ }^{2}$ Bagian Kesehatan dan Keselamatan Kerja Universitas Islam Negeri Alauddin Makassar \\ ${ }^{3}$ Bagian Epidemiologi Universitas Islam Negeri Alauddin Makassar
}

\begin{abstract}
ABSTRAK
Pendidikan seksual anak usia dini menjadi salah satu upaya untuk mencegah berbagai bahaya kejahatan seksual dan penyimpangan seksual pada anak. Keluarga menjadi wadah utama bagi anak untuk memperoleh pendidikan, termasuk pendidikan seksual. Penelitian ini betujuan untuk mengetahui gambaran pendidikan seksual anak usia dini dalam keluarga sejahtera III plus di Kecamatan Tallo.Jenis penelitian yang digunakan adalah penelitian kuantitatif dengan pendekatan deskriptif survei pada keluarga sejehtera III plus di Kecamatan Tallo.Dari populasi 567 keluarga diperoleh sampel sebanyak 180 keluarga menggunakan purposive sampling dengan kriteria keluarga sejahtera III plusyang memiliki anak usia 8-12 tahun.Hasil penelitian menunjukkan sebagian besar responden memiliki pengetahuan yang baik $(93,4 \%)$, kontrol diri yang baik $(51,7 \%)$, sikap positif $(93,4 \%)$, tindakan yang baik $(81,1 \%)$, lingkungan sosial yang baik $(82,2 \%)$ dalam memberikan pendidikan seksual anak dalam keluarga. Sehingga pendidikan seksual anak usia dini pada keluarga sejahtera III plus di kecamatan Tallo sudah baik, meskipun masih terdapat beberapa responden yang tidak pernah memberikan pendidikan seksual dalam keluarganya $(41,1 \%)$. Oleh karena itu, orang tua diharapkan secara aktif dan terbuka dalam berkomunikasi masalah seksual dengan anak serta menjadi teladan dengan menanamkan nilai keislaman dalam kehidupan sehari-hari merupakan bagian dari pendidikan seksual anak usia dini dalam keluarga
\end{abstract}

Kata Kunci : Pendidikan Seksual, Anak Usia Dini, Keluarga.

\section{PENDAHULUAN}

Munculnya berbagai penyimpangan seksual terhadap anak-anak dan remaja semakin meresahkan orang tua. Berbagai penyimpangan seksual yang sering ditemui adalah kekerasan seksual ,seks bebaspada anak yang muncul akibat kurangnya pemahaman tentang permasalahan seksual dan tingginya rasa ingin tahu anak-anak terha- dap permasalahan seksual (Anugraheni dkk, 2012).

Menutup informasi masalah seksual kepada anak justru kurang bijaksana bagi proses pendidikan seks anak dan keluarga karena masalah seksual tidak hanya selalu masalah hubungan intim, tetapi mencakup banyak elemen seperti pemahaman alat kelamin secara biologis, fisiologis dan fungsi 
hormonal, pemahaman gender dan seksualitas, pemahaman hasrat seksualitas, pemahaman komunikasi seksualitas, pemahaman sumber rangsangan seksualitas, pemahaman akil baligh, pemahaman seksualitas pada anak, remaja, dewasa dan usia lanjut, pemahaman hak pilih anak, pemahaman orientasi seksualitas, pemahaman unsur genetis seksualitas, pemahaman kejahatan seksualitas dan hukumnya, pemahaman kebijakan publik berkaitan dengan aspek seksualitas masyarakat.

Survei yang dilakukan oleh Komite Perlindungan Anak Indonesia (KPAI) dan Kementrian Kesehatan Republik Indonesia (Kemenkes RI) pada Oktober 2013 memaparkan grafik bahwa sekitar $62,7 \%$ remaja di Indonesia telah melakukan hubungan seks di luar nikah. 20\% dari 94.270 perempuan yang mengalami hamil di luar nikah juga berasal dari kelompok usia remaja dan $21 \%$ diantaranya pernah melakukan aborsi (Kementerian Kesehatan RI, 2014). Lalu menurut Nurrachman (2010) pada kasus terinfeksi HIV dalam rentang 3 bulan sebanyak 10.203 kasus, $30 \%$ penderitanya berusia remaja.Bahkan 92,7\% remaja yang disurvei mengaku pernah berciuman, petting, hingga melakukan oral seks.Data tersebur menunjukkan bahwa sudah parahnya kehidupan remaja dan anak muda di Indonesia saat ini.

Sementara itu, menurut Setyawan
(2015) dalam tulisannya "Komisi Perlindungan Anak darurat kejahatan seksual anak," 62 persen dari semua kasus pelanggaran terhadap anak itu adalah kejahatan seksual. Sebaran masalahnya bukan hanya terjadi di lingkungan terdekat anak dan perkotaan, tapi sudah merambah hingga ke pelosok desa.

Sebagaimana pendidikan dengan materi apapun strategi pendidikan seks harus disesuaikan dengan tingkat kedalaman materi, tujuan, usia anak, tingkat pengetahuan dan kedewasaan anak, serta media yang dimiliki oleh pendidik (keluarga). Apabila dikaitkan dengan budaya lokal, penjelasan harus sesuai tradisi lokal yang positif, moral, dan ajaran agama.

Berdasarkan tahapan perkembangan seksual(Kriswanto, 2006), anak usia 8-12 tahun berada pada tahap anak dan pra remaja, dimana pada tahap ini anak belajar bersosialisasi dan menyongsong masa puber, sehingga pada masa ini merupakan masa yang tepat untuk memberikan pendidikan seks pada anak dalam keluarga.

Orang tua dalam keluarga memiliki peranan besar terhadap proses pendidikan seks seorang anak. Kondisi dan latar belakang keluarga yang berbeda memungkinkan adannya perbedaan pendidikan yang diberikan kepada anak. Dalam UndangUndang (UU) No. 52 Tahun 2009 terdapat 21 indikator keluarga sejahtera yang meng- 
gambarkan bagaimana keluarga memenuhi kebutuhannya dan dikelompokkan menjadi keluarga prasejahtera, keluarga sejahtera I, keluarga sejahtera II, keluarga sejahtera III dan keluarga sejahtera III plus.

Untuk itu perlu diketahui lebih dalam bagaimana pola pengajaran dan pendidikan seksual anak usia dini dalam keluarga pada keluarga sejahtera III plus atau keluarga yang memenuhi 21 indikator keluarga sejahtera III (tingkat kebutuhan) di kota Makassar, khususnya di Kecamatan Tallo.

\section{BAHAN DAN METODE}

\section{Jenis dan Lokasi Penelitian}

Penelitian ini dilaksanakan di Kecamatan Tallo, KotaMakassar, Sulawesi Selatan. Adapun penelitian yang digunakan adalah jenis penelitian kuantitatif, dengan model penelitian survei, yang bersifat deskriptif bertujuan untuk memperoleh gambaran tentang pendidikan seksual anak usia dini dalam keluarga sejahtera III plus di Kecamatan Tallo, Kota Makassar.

\section{Populasi dan Sampel}

Populasi dalam penelitian ini adalah seluruh keluarga yang ada di Kecamatan Tallo, Kota Makassar dengan populasi terjangkau adalah seluruh Keluarga Sejahtera II Plus yang bermukim di Kecamatan Tallo sebanyak 546 keluarga.Adapun sampel dalam penelitian ini diperoleh melalui me- tode purposive sampling sebanyak 180 orang responden.

\section{Pengumpulan Data}

Data primer diperoleh melalui melalui wawancara langsung kepada responden maupun responden mengisi langsung kuisioner yang telah disediakan mengenai gambaran pendidikan seksual anak usia dini.

Data sekunder data yang diperoleh dari Badan Pusat Statistik Kota Makassar, Pemerintah Kecamatan Tallodan Kader Kecamatan Tallo.Selain itu data sekunder juga diperoleh dari buku referensi dan bersumber dari internet.

\section{Instrument Penelitian}

Instrumenpenelitian yang digunakandalam proses pengumpulan data adalahkuisionerdengan menggunakan pertanyaan tertutup dan beberapa pertanyaan terbuka. Kuisioner pertanyaan yang terbagi dalam lima variabel, yakni pengetahuan, kontrol diri, sikap, dan tindakan orang tua, serta lingkungan sosial keluarga terkait pendidikan seksual anak usia dini dalam keluarga.

\section{HASIL PENELITIAN}

Pada tabell hubungan pengetahuan orang tua dengan pendidikan seksual anak usia dini dalam keluarga di Kecamatan 
Tallo Kota Makassar tahun 2016 dapat disimpulkan bahwa pada orang tua dengan pengetahuan yang baik terdapat $57,2 \%$ pernah memberikan pendidikan seksual anak usia dini dan $36,1 \%$ tidak pernah memberikan pendidikan seksual anak usia dini, sedangkan dari orang tua dengan pengetahuan kurang, terdapat $5,0 \%$ yang tidak pernah memberikan pendidikan seksual anak usia kan orang tua dengan kontrol diri kurang terdapat $22,2 \%$ yang tidak pernah memberikan pendidikan seksual anak usia dini dan $26,1 \%$ pernah memberikan pendidikan seksual anak usai dini.

Berdasarkan table 3 hubungan sikap orang tua dengan pendidikan seksual anak usia dini dalam keluarga di Kecamatan Tallo Kota Makassar tahun 2016dapat dis-

Tabel 1. Hubungan Pengetahuan Orang Tua dengan Pendidikan Seksual Anak Usia Dini dalam Keluarga

\begin{tabular}{lcccccc}
\hline \multirow{2}{*}{$\begin{array}{l}\text { Pengetahuan Orang } \\
\text { Tua }\end{array}$} & \multicolumn{2}{c}{ Pendidikan Seksual Anak Usia Dini } & \multicolumn{2}{c}{ Jumlah } \\
\multirow{2}{*}{ Baik } & $\mathrm{N}$ & $\%$ & $\mathrm{~N}$ & $\%$ & $\mathrm{n}$ & $\%$ \\
Kurang & 103 & 57,2 & 65 & 36,1 & 168 & 93,4 \\
Jumlah & 3 & 1,6 & 9 & 5,0 & 12 & 6,6 \\
\hline
\end{tabular}

Sumber: Data Primer, 2016

dini dan 1,6\% pernah memberikan pendidikan seksual anak usia dini (Data primer, 2016).

Berdasarkan tabel 2 hubungan kontrol diri orang tua dengan pendidikan seksual anak usia dini dalam keluarga di Kecamatan Tallo Kota Makassar tahun 2016 dapat disimpulkan bahwa orang tua dengan kontrol diri yang baik terdapat $32,8 \%$ pernah memberikan pendidikan seksual anak usia dini dan 18,9\% dengan kontrol diri baik tapi yang tidak pernah memberikan pendidikan seksual anak usia dini. Sedang- impulkan bahwa orang tua dengan sikap yang baik terdapat $36,7 \%$ tidak pernah memberikan pendidikan seksual anak usia dini dan $56,7 \%$ pernah memberikan pendidikan seksual anak usia dini, sedangkan orang tua dengan sikap kurang terdapat $4,4 \%$ yang tidak pernah memberikan pendidikan seksual anak usia dini dan 2,2\% pernah memberikan pendidikan seksual anak usai dini.

Berdasarkan tabel 4 hubungan tindakan orang tua dengan pendidikan seksual anak usia dini dalam keluarga di Kecamatan 
Tallo Kota Makassar tahun 2016dapat disimpulkan bahwa orang tua dengan tindakan kurang $15,0 \%$ tidak pernah memberikan pendidikan seksual anak usia dini dan 3,9\% pernah memberikan pendidikan seksual anak usai dini. Sedangkan orang tua dengan tindakan yang baik 26,1\% tidak pernah memberikan pendidikan seksua anak usia dini 55,0\% pernah memberikan pendidikan didikan seksual anak usia dini dan 8,3\% pernah memberikan pendidikan seksual anak usai dini.

Sehingga pendidikan seksual anak usia dini secara umum pernah diberikan oleh orang tua dalam keluarga dengan presentasi $58,9 \%$ orang tua pernah memberikan pendidikan seksual dan $41,1 \%$ orang tua tidak pernah memberikan pendidikan

Tabel 2. Hubungan Kontrol Diri Orang Tua dengan Pendidikan Seksual Anak Usia Dini dalam Keluarga

\begin{tabular}{lcccccc}
\hline \multirow{2}{*}{$\begin{array}{c}\text { Kontrol Diri Orang } \\
\text { Tua }\end{array}$} & \multicolumn{2}{c}{ Pendidikan Seksual Anak Usia Dini } & \multicolumn{2}{c}{ Jumlah } \\
\multirow{2}{*}{ Baik } & $\mathrm{N}$ & $\%$ & $\mathrm{~N}$ & $\%$ & $\mathrm{n}$ & $\%$ \\
Kurang & 59 & 32,8 & 34 & 18,9 & 93 & 51,7 \\
Jumlah & 47 & 26,1 & 40 & 22,2 & 87 & 48,3 \\
\hline
\end{tabular}

Sumber: Data Primer, 2016

seksual anak usia dini.

Berdasarkan tabel 5 hubungan lingkungan sosial keluarga dengan pendidikan seksual anak usia dini dalam keluarga di Kecamatan Tallo Kota Makassar tahun 2016 dapat disimpulkan bahwaorang tua dengan lingkungan sosial keluarga yang baik $31,7 \%$ tidak pernah memberikan pendidikan seksual anak usia dini dan 50,6\% pernah memberikan pendidikan seksual anak usia dini, sedangkan orang tua dengan lingkungan keluarga sosial yang kurang 9,4\% yang tidak pernah memberikan pen- seksual anak usia dini.

\section{PEMBAHASAN}

Berdasarkan hasil penelitian yang telah dipaparkan sebelumnya, maka dapat disimpulkan bahwa sebagian besar orang tua pernah memberikan pendidikan seksual anak usia dini dalam keluarga dengan presentas $58,9 \%$.

Berdasarkan hasil penelitian, pendidikan seksual anak usia dini dalam keluarga dipengaruhi oleh tingkat pengetahuan orang tua, kontrol diri orang tua, si- 
kap dan tindakan orang tua, serta lingkungan sosial keluarga yang saling mepengaruhi satu sama lain. Secara keseluruhan setiap variabel tersebut memperlihatkan bahwa responden memiliki penilaian yang baik dan positif dalam memberikan pendidikan seksual anak usia dini.

Namun, beberapa responden dengan penilaian baik dan positif tersebut di atas tidak pernah memberikan pendidikan sek- sekarang lebih kritis, dari segi pertanyaan dan tingkah laku karena pada masa ini anakanak memiliki rasa keingintahuan yang besar.Pendidikan seks dalam keluarga merupakan salah satu alternatif dalam membekali anak-anak dengan informasi-informasi tentang seks, kesehatan, dan masalah-masalah reproduksi secara benar (Herjanti, 2015).

Selain anggapan tabu di masyarakat, dalam penelitian Fauziyah dan Rohman

Tabel 3. Hubungan Sikap Orang Tua dengan Pendidikan Seksual Anak Usia Dini dalam Keluarga

\begin{tabular}{|c|c|c|c|c|c|c|}
\hline \multirow{3}{*}{ Sikap Orang Tua } & \multicolumn{4}{|c|}{ Pendidikan Seksual Anak Usia Dini } & \multirow{2}{*}{\multicolumn{2}{|c|}{ Jumlah }} \\
\hline & \multicolumn{2}{|c|}{ Pernah } & \multicolumn{2}{|c|}{ Tidak Pernah } & & \\
\hline & $\mathrm{N}$ & $\%$ & $\mathrm{~N}$ & $\%$ & $\mathrm{n}$ & $\%$ \\
\hline Positif & 102 & 56,7 & 66 & 36,7 & 168 & 93,4 \\
\hline Negatif & 4 & 2,2 & 8 & 4,4 & 12 & 6,6 \\
\hline Jumlah & 106 & 58,9 & 74 & 41,1 & 180 & 100 \\
\hline
\end{tabular}

Sumber: Data Primer, 2016

sual dalam keluarganya.Hal ini terjadi karena sebagaian responden menganggap pendidikan seks masih tabu. Selama ini, pendidikan seks untuk anak usia dini dianggap tabu di kalangan masyarakat.

Orang tua beranggapan bahwa pendidikan seks belum pantas diberikan pada anak kecil.Padahal dengan pendidikan seks yang diberikan sejak dini sangat berpengaruh dalam kehidupan anak ketika mereka memasuki masa remaja.Apalagi anak-anak
(2012) dibutuhkan kemampuan, keterampilan, keterbukaan dan kemauan orang tua dalam memberikan pendidikan seks akan menentukan perasaan anak pada masa yang akan mendatang. Pendidikan seksual bagi anak menekankan bahwa pendidikan seksual hendaknya diberikan bersamaan dengan pendidikan agama dan moral, dimana pendidikan agama dan pendidikan moral menjadi dasar pendidikan seksual.

Dalam Islam telah dijelaskan berba- 
gai pembiasaan-pembiasaan seperti pembiasaan meminta izin ketika memasuki kamar orang dewasa.Seperti yang telah dijelaskan dalam Surah An-Nuur/24 Ayat 58 yang terjemahnya:

Hai orang-orang yang beriman, hendaklah budak-budak (lelaki dan wanita) yang kamu miliki, dan orang-orang yang belum balig di antara kamu, meminta izin kepada kamu tiga kali (dalam satu hari) Yaitu: sebelum sembahyang subuh, yang mengarahkan manusia pada norma sosial dalam lingkungan keluarga. Ia merupakan perintah buat orang tua agar mendidik anak-anak dan bawahannya agar memerhatikan norma-norma pergaulan (Shihab, 2002).

Ayat tersebut telah menggambarkan bagaimana adat moral dan agama sejalan dengan pembiasaan pendidikan seks pada anak.Sebagian besar responden dalam

Tabel 4. Hubungan Tindakan Orang Tua dengan Pendidikan Seksual Anak Usia Dini dalam Keluarga

\begin{tabular}{|c|c|c|c|c|c|c|}
\hline \multirow{3}{*}{ Tindakan Orang Tua } & \multicolumn{4}{|c|}{ Pendidikan Seksual Anak Usia Dini } & \multirow{2}{*}{\multicolumn{2}{|c|}{ Jumlah }} \\
\hline & \multicolumn{2}{|c|}{ Pernah } & \multicolumn{2}{|c|}{ Tidak Pernah } & & \\
\hline & $\mathrm{N}$ & $\%$ & $\mathrm{~N}$ & $\%$ & $\mathrm{n}$ & $\%$ \\
\hline Baik & 99 & 55,0 & 47 & 26,1 & 146 & 81,1 \\
\hline Kurang & 7 & 3,9 & 27 & 15,0 & 34 & 18,9 \\
\hline Jumlah & 106 & 58,9 & 74 & 41,1 & 180 & 100 \\
\hline
\end{tabular}

Sumber: Data Primer, 2016

ketika kamu menanggalkan pakaian (luar)mu di tengah hari dan sesudah sembahyang Isya'. (Itulah) tiga 'aurat bagi kamu.Tidak ada dosa atasmu dan tidak (pula) atas mereka selain dari (tiga waktu) itu. Mereka melayani kamu, sebahagian kamu (ada keperluan) kepada sebahagian (yang lain). Demikianlah Allah menjelaskan ayat-ayat bagi kamu.dan Allah Maha mengetahui lagi Maha Bijaksana"'(Kementerian Agama Republik Indonesia, 2012).

Ayat ini merupakan salah satu ayat penelitian ini menganggap bahwa kebiasaan, adat istiadat, agama bukan menjadi penghambat dalam memberikan pendidikan seksual dalam keluarga.

Dalam penelitian ini, terdapat beberapa keluarga yang yang tidak pernah memberikan pendidikan seksual karena memiliki pengetahuan, kontrol diri, sikap, tindakan dan lingkungan sosial yang kurang.Penelitian yang dilakukan oleh Lestari dan Presetyo (2014) menjelaskan 
bahwa tidak adanya pendidikan seksual dalam keluarga sangat mempengaruhi perkembangan dan perilaku seksual anak di masa yang akan datang. Sebagian besar para pelanggar seks berasal dari keluarga dimana orangtua tidak banyak atau bahkan sama dan adat istiadat sebagian besar orang tua tidak bertentang dengan pendidikan seksual anak usia dini, meskipun masih ada sebagian orang tua yang menganggap hal tersebut penghambat pendidikan seksual anak usia dini.Hal ini sejalan dengan peneli-

\section{Tabel 5. Distribusi Hubungan Lingkungan Sosial Keluarga dengan Pendidikan Seksual Anak Usia Dini dalam Keluarga}

\begin{tabular}{|c|c|c|c|c|c|c|}
\hline \multirow{3}{*}{$\begin{array}{l}\text { Lingkungan Ke- } \\
\text { luarga }\end{array}$} & \multicolumn{4}{|c|}{ Pendidikan Seksual Anak Usia Dini } & \multirow{2}{*}{\multicolumn{2}{|c|}{ Jumlah }} \\
\hline & & & & ernah & & \\
\hline & $\mathrm{N}$ & $\%$ & $\mathrm{~N}$ & $\%$ & $\mathrm{n}$ & $\%$ \\
\hline Baik & 91 & 50,6 & 57 & 31,7 & 148 & 82,3 \\
\hline Kurang & 15 & 8,3 & 17 & 9,4 & 32 & 17,7 \\
\hline Jumlah & 74 & 41,1 & 106 & 58,9 & 180 & 100 \\
\hline
\end{tabular}

Sumber: Data Primer, 2016

sekali tidak memberikan pendidikan seks kepada anak.

Lingkungan sosial masyarakat turut mendukung pendidikan seksual anak dalam keluarga, dalam penelitian ini responden berasal dari latar belakang keluarga modern dan sejahtera sehingga informasi, perkembangan media dan keterbukaan orang tua menerima informasi bersifat fleksibel.Namun, perkembangan media informasi juga memiliki dampak buruk yang mempengaruhi perkembangan seksual anak sehingga pendidikan seksual sejak dini sangat diperlukan dalam keluarga.

Berdasarkan hasil penelitan diketahui bahwa nilai, norma, kebiasaan, agama tian yang dilakukan oleh Imanda Kartika Putri tahun 2012, dimana budaya, adat istiadat dan ajaran agama islam menjadi penghambat pemberian pendidikan seksual sebagain kecil orang tua.

\section{KESIMPULAN}

Adapun kesimpulan dari penelitian ini adalah $58,9 \%$ orang tua pernah memberikan pendidikan seksual anak usia dini dalam keluarga dan $41,1 \%$ tidak pernah memberikan pendidikan seksual anak usia dini. Pengetahuan orang tua tentang pendidikan seksual anak usia dini dalam keluarga sudah baik, namun terdapat $36,1 \%$ responden dengan pengetahuan baik tetapi 
tidak pernah memberikan pendidikan seks kepada anaknya. Kontrol diri orang tau terhadap pendidikan seksual anak usia dini dalam sudah baik, namun terdapat 22,2\% responden dengan kontrol diri yang baik tetapi tidak pernah memberikan pendidikan seks kepada anaknya. Sikap orang tua terhada pendidikan seksual anak usia dini dalam keluarga sudah positif, namun masih terdapat $36,7 \%$ responden dengan sikap yang positif tetapi tidak pernah memberikan seks dalam keluarganya. Tindakan orang tua tentang pendidikan seksual anak usia dini dalam keluarga sudah baik, namun terdapat $26,1 \%$ responden dengan tindakan yang baik tetapi tidak memberikan pendidikan seksual dalam keluarganya. Lingkungan sosial keluarga terhadap pendidikan seksual anak usia dini dalam keluarga sudah baik, namun 31,7\% responden dengan lingkungan sosial yang baik tetapi tidak pernah memberikan pendidikan seksual anak usia dini.

\section{SARAN}

Saran yang dapat diberikan setelah melihat kesimpulan dari penelitian ini adalah sebagai berikut;Orang tua diharapkan agar aktif dan terbuka dalam berkomunikasi masalah seksual dengan anak, serta menjadi teladan yang baik sesuai dengan menanamkan nilai-nilai dalam kehidupan anak sehari-hari. Institusi yang terkait dengan pendidikan seksual anak usia dini perlu memberikan perhatian dalam membuat kebijakan pendidikan seksual anak.

\section{DAFTAR PUSTAKA}

Anugraheni, E., dkk. (2012) Hubungan Pengetahuan dan Sikap Orang Tua Tentang Pendidikan Seks dengan Tindakan Orang tua dalam pemberian Pendidikan Seks pada Remaja (Studi di Kecamatan Sumbersari Kabupaten Jember). Artikel Ilmiah Hasil Penelitian Mahasiswa 2012 Universitas Jember, 1-6

Fauziyah S., \& Rohman M. (2012). Pendidikan Seks Bagi Anak. JurnalPrimary, Volume 4 No.2, 159-180.

Herjanti. (2015). Pola Asuh Orang Tua tentang Pendidikan Seks Anak Usia Dini. Jurnal Ilmu Kebidanan Indonesia, Vol. 05 No. 02, 93-106.

Kementerian Agama Republik Indonesia. (2012). Al-Qur'an dan Terjemahannya. Jakarta: Kementerian Agama

Kementerian Kesehatan RI. (2014). Gerakan Nasional Anti Kejahatan Seksual pada Anak (GN-AKSA). Jakarta: Direktorat Bina Kesehatan Anak Kementerian Kesehatan RI

Kriswanto C. (2006). Seks, Es Krim, dan Kopi Susu. Jakarta: Jagadnita Publishing

Lestari E., \& Prasetyo J. (2014). Peran Orang Tua dalam Memberikan Pendidikan Seks Sedini Mungkin di TK Mardisiwi Desa Kedondong Kecamatan Kebonsari Kabupaten Madiun. JurnalNugroho, 2:124 131

Nurrachman, K. I. Seks Bebas Jadi Gaya Hidup?,2010. Diakses pada tanggal 1 Mei 2014 di http:// news.okezone.com/

Putri, Kartika Imanda. (2012). FaktorFaktor Yang Berhubungan dengan 
Perilaku Pemberian Pendidikan Seks Untuk Anak Oleh Orang Tua Siswa Madrasah Ibtidaiyah Hayatullah Islamiyah Depok Tahun 2012.Jurnal FKM Universitas Indonesia.

Setyawan, D. (2015). Komisi Perlindungan Anak Indonesia Darurat Kejahatan
Seksual Anak. Retrieved January 13, 2016, from http://www.kpai.go.id/ berita/indonesia-darurat-kejahatan$\underline{\text { seksual-anak/ }}$

Shihab M. Q. (2002). Tafsir Al-Misbah: pesan, kesan, dan keserasian AlQur'an. Jakarta: Lentera Hati 